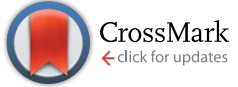

Cite this: RSC Adv., 2016, 6, 17256

Received 30th September 2015 Accepted 4th February 2016

DOI: $10.1039 / c 5 r a 20221 c$

www.rsc.org/advances

\section{Modification of nanostructured ZnO surfaces with curcumin: fluorescence-based sensing for arsenic and improving arsenic removal by $\mathrm{ZnO}$}

\begin{abstract}
Rasha N. Moussawi and Digambara Patra*
Applying a simple aqueous phase chemistry method, nanostructured zinc oxide surfaces have been modified with curcumin, here referred to as $\mathrm{Zn}$ (cur)O. The morphology of these $\mathrm{Zn}$ (cur)O nanostructured materials is a grain-like wurtzite hexagonal crystal structure with good crystalline quality. Doping of curcumin fills the defects of $\mathrm{ZnO}$ that are visible luminescence centers and prolongs electron-hole recombination, resulting, respectively, in quenching of visible luminescence and an enhancement in the exciton emission of $\mathrm{ZnO}$. The photoluminescence of $\mathrm{ZnO}$ is insensitive to arsenic concentration in water, but the photoluminescence of a $\mathrm{Zn}(\mathrm{cur}) \mathrm{O}$ colloidal solution at an excitation wavelength of $425 \mathrm{~nm}$ can sensitively sense arsenic in the concentration range 100 to $3000 \mathrm{ppb}$. At the same time $\mathrm{Zn}$ (cur)O can significantly improve the efficient removal of arsenic contamination from water below the maximum contaminant level $(\mathrm{MCL})$ within 30 minutes and almost to zero in $3 \mathrm{~h}$ without oxidation and/or $\mathrm{pH}$ adjustment. The adsorption kinetics during arsenic removal by $\mathrm{Zn}(\mathrm{cur}) \mathrm{O}$ obeys a pseudo-second order model with exceptional adsorption rates compared to $\mathrm{ZnO}$, reflecting the high affinity of $\mathrm{Zn}$ (cur)O nanomaterials to arsenic due to improvement in adsorption.
\end{abstract}

\section{Introduction}

The design of functional nanomaterials has fuelled the advance of nanomaterials and nanotechnology through the production of special materials with novel properties for potential applications in chemical, biological, and technological domains. Incorporating functionalities of organic systems on the surface of metal oxide nanoparticles will yield hybrid materials with novel properties and functions. ${ }^{1,2}$ Zinc oxide has presented itself as a special material with great potential and thus has attracted research to study this semiconductor in the form of powders, single crystals, thin films, or nanostructures. ZnO has a wide band gap $\left(\sim 3.37 \mathrm{eV}\right.$ at room temperature $\left.{ }^{3}\right)$ and its high excitonbinding energy $(60 \mathrm{meV})^{3}$ allows efficient excitonic emission even at room temperature. ${ }^{4}$ Although a small amount of $\mathrm{ZnO}$ dissolves and releases zinc ion into water, $\mathrm{ZnO}$ is biocompatible rendering it suitable for biomedical and environmental applications such as, transparent conducting electrodes in solar cells, ${ }^{5}$ photocatalysts for degradation of organic pollutants in wastewaters, ${ }^{6} \mathrm{UV}$ lasers, ${ }^{7}$ and chemical and biological sensors. ${ }^{8}$

Arsenic contamination in natural water renders the lives of millions of people around the world at risk. Exposure to arsenic over extended periods of time leads to serious health problems, such as cancers of liver, lung, kidney, bladder, and skin, ${ }^{\mathbf{9 , 1 0}}$ cardio vascular system problem, ${ }^{\mathbf{1 1}}$ and affects the mental

Department of Chemistry, American University of Beirut, Beirut, Lebanon. E-mail: dp03@aub.edu.lb; Fax: +9611365 217; Tel: +961 1350000 ext. 3985 development of children. ${ }^{12}$ Arsenic in natural water can be the result of leaching from arsenic containing source rocks and sediments. Its presence is generally associated to geochemical environments such as basin-fill deposits of alluvial lacustrine origin, volcanic deposits, inputs from geothermal sources, mining wastes and land fills. ${ }^{\mathbf{1 3} 14}$ In 2001, the US Environmental Protection Agency (EPA) lowered the maximum contaminant level (MCL) for arsenic in drinking water from 50 to $10 \mu \mathrm{g} \mathrm{L}^{-1}$ $(0.01 \mathrm{ppm})^{15}$ which rendered the drinking sources all over the world unacceptable. The arsenic contamination of the groundwater has been a serious problem in many countries. Therefore, research on arsenic detection and removal from drinking water using low-cost and simple methods has greatly increased. The conventional methods ${ }^{\mathbf{1 5}}$ for arsenic treatment include coagulation and flocculation, precipitation, adsorption, ion exchange, and membrane filtration. Alternative unconventional methods like ozone oxidation, bioremediation and electro-chemical treatments are also used in the removal of arsenic. Among the various arsenic removal techniques, adsorption seems to be the simplest, cost-effective, and safer to handle process than precipitation, ion exchange, and membrane filtration.

Arsenic exists in water as two major inorganic arsenic species, namely $\mathrm{As}(\mathrm{III})$ (arsenite, $\mathrm{AsO}_{3}{ }^{3-}$ ) and $\mathrm{As}(\mathrm{v})$ (arsenate, $\mathrm{AsO}_{4}{ }^{3-}$ ). The existence and ratio of these two forms of arsenic is dependent greatly on $\mathrm{pH}$ and the redox conditions of the environment in which they are present. Arsenates are stable under aerobic or oxidizing conditions, while arsenites are stable under 
anaerobic or mildly reducing conditions. ${ }^{15}$ Arsenite species exists in solution as $\mathrm{H}_{3} \mathrm{AsO}_{3}$ (arsenous acid) and $\mathrm{H}_{2} \mathrm{AsO}_{3}{ }^{-}$ (dihydrogen arsenite) with $\mathrm{p} K_{\mathrm{a}}$ values of 9.2 and 12.7 respectively. ${ }^{16}$ Arsenate species is present as $\mathrm{H}_{2} \mathrm{AsO}_{4}{ }^{-}$(dihydrogen arsenate) and $\mathrm{HAsO}_{4}{ }^{2-}$ (arsenate hydrogen ion) and the $\mathrm{p} K_{\mathrm{a}}$ values for arsenic acid $\left(\mathrm{H}_{3} \mathrm{AsO}_{4}\right)$ are $\mathrm{p} K_{\mathrm{a} 1}=2.3, \mathrm{p} K_{\mathrm{a} 2}=6.8$, and $\mathrm{p} K_{\mathrm{a} 3}=11.6 .^{16}$ Of these two redox states of As, arsenite As(III) is the more toxic form than arsenate. Also, arsenate is easier to remove from water than arsenite, as it is an ionic species in the $\mathrm{pH}$ range typically found in the aquatic environment. ${ }^{17}$ Arsenite, on the other hand, exists in nonionic form $\mathrm{H}_{3} \mathrm{AsO}_{3}$ in natural water with $\mathrm{pH}$ value ranging from weakly acidic to weakly alkaline, which renders the adsorption performance of various adsorbents on $\mathrm{As}(\mathrm{III})$ poor. ${ }^{18-20}$ It would require additional oxidizers to oxidize arsenite to arsenate if $\mathrm{pH}$ is less than $10 .^{17}$ Thus, oxidizing As(III) to As(v) and/or pH adjustment becomes necessary for its effective removal from water before coagulation-precipitation or adsorption processes. ${ }^{21-23}$ As this would add to the complexity and cost of the treatment process, adsorbents able to effectively remove As(III) without the oxidation/pH adjustment is being developed.

$\mathrm{ZnO}$ acts as a good adsorbent, but so far it has its own limitations. Doping with organic system may influence adsorption and luminescence properties of $\mathrm{ZnO}$. The sensitization of $\mathrm{ZnO}$ towards visible light means the band gap has to be narrowed or split into several sub-gaps. This has been done through various methods such as surface modification by incorporation of organic materials, ${ }^{24}$ fullerenes ${ }^{25}$ and polymers. ${ }^{26-28}$ However, research work on dye doped zinc oxides and their respective optical and catalytic properties remains narrowed. Curcumin (see Scheme 1) accounts as the major component in the curcuminoid complexes and well known for its pharmaceutical applications and medicinal potential in therapy of many diseases such as, cancer, cardiovascular disease, and rheumatoid arthritis. ${ }^{29-31}$ Reports on curcumin as sensitizer are scarce. Curcumin-derived dye can be used as a sensitizer in dye sensitized solar cells with photocurrent density of $1.66 \mathrm{~mA} \mathrm{~cm}^{2} \cdot{ }^{32}$ Curcumin has very exciting photophysical and fluorescence properties. ${ }^{33}$ Curcumin, as fluorescence probe for developing new sensing scheme, is getting widely realised..$^{34-36}$ It can act as a reducing agent to prepare metal nanoparticles ${ }^{37}$ and nanorods ${ }^{\mathbf{3 8}}$ and make metal complex with various metal ions. ${ }^{39-41}$ It also forms a $\mathrm{Zn}$-curcumin complex by reacting with zinc salt. ${ }^{\mathbf{4 2}}$ Curcumin has also been used to prepare $\mathrm{ZnO}$-curcumin composites. ${ }^{\mathbf{4 3 - 4 5}}$ However, there is no literature work where curcumin is doped on $\mathrm{ZnO}$ surfaces. In this work we attempted to prepare a new curcumin doped $\mathrm{ZnO}$ nanomaterials, which is termed here as $\mathrm{Zn}$ (cur)O, and apply it for developing new fluorescence sensing scheme for arsenic as depicted in Scheme 2 and at the same time quick removal of arsenic from water without the oxidation and/or $\mathrm{pH}$ treatment.

\section{Materials and methods}

\subsection{Materials}

Zinc nitrate hexahydrate $\left(\mathrm{Zn}\left(\mathrm{NO}_{3}\right)_{2} \cdot 6 \mathrm{H}_{2} \mathrm{O}\right)$ (98\% extra pure) was obtained from Acros Organics. Curcumin was received from Sigma and acetone (HPLC grade) was used from Aldrich. Potassium hydroxide was sourced from AnalaR. A primary stock element reference solution of arsenic (As(III), 1000 ppm, matrix: $0.5 \mathrm{M} \mathrm{HNO}_{3}$ ) was supplied by Romil LTD and stored in the dark in a refrigerator. All the solutions were prepared with deionized water unless otherwise mentioned.<smiles>C=CCOc1ccc(/C=C/C2=CC(/C=C/c3ccc(O)c(OC)c3)=C/C(=C\c3ccc(O)c(OC)c3)OC2)cc1OC</smiles>

Scheme 1 Structure of curcumin.

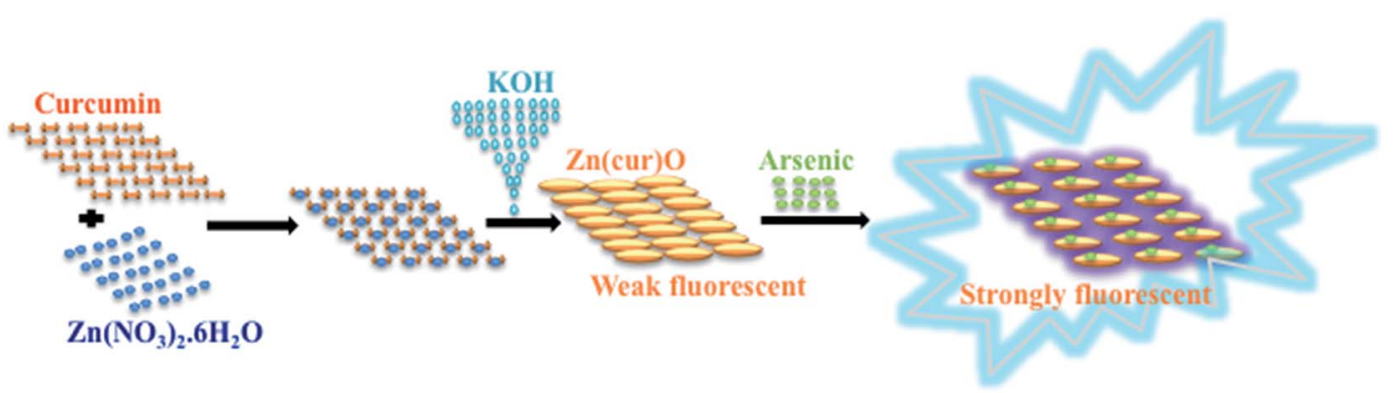

Scheme 2 Schematic illustration of synthesis of $\mathrm{Zn}(\mathrm{cur}) \mathrm{O}$ followed by fluorescence enhancement of $\mathrm{Zn}$ (cur)O upon binding with arsenic in water. 


\subsection{Synthesis}

$\mathrm{Zn}$ (cur)O was prepared by taking $0.5( \pm 0.1) \mathrm{mg}, 1.0 \mathrm{mg}( \pm 0.1)$, or $2.0( \pm 0.1) \mathrm{mg}$ of curcumin in $50 \mathrm{~mL}$ of double distilled water (close to neutral $\mathrm{pH}$ ) at $80-90{ }^{\circ} \mathrm{C}$. The relatively high temperature was useful for $\mathrm{ZnO}$ synthesis. When curcumin was solubilized completely, $50 \mathrm{~mL}$ of $0.1 \mathrm{M} \mathrm{Zn}\left(\mathrm{NO}_{3}\right)_{2}$ solution prepared in double distilled water was added to it. The yellowish solution was refluxed for 1 hour at $85-90{ }^{\circ} \mathrm{C}$. After that, the solution was cooled down and $5 \mathrm{~mL}$ of $0.2 \mathrm{M} \mathrm{KOH}$ was added slowly at $4{ }^{\circ} \mathrm{C}$. An orange yellow gel-like suspension was observed. The solution was centrifuged at $5000 \mathrm{rpm}$ and the precipitate was washed with water till no more yellow color was observed in the supernatant. Acetone washes were necessary to remove any unanchored curcumin after which the final wash was with water. The precipitate $\mathrm{Zn}$ (cur)O was vacuum dried at room temperature. A control $\mathrm{ZnO}$ was synthesized by taking $50 \mathrm{~mL}$ of $0.1 \mathrm{M} \mathrm{Zn}\left(\mathrm{NO}_{3}\right)_{2}$ solution prepared in double distilled water and then adding $5 \mathrm{~mL}$ of $0.2 \mathrm{M} \mathrm{KOH}$ slowly in an ice bath at $4{ }^{\circ} \mathrm{C}$. The white suspension was centrifuged at $5000 \mathrm{rpm}$, washed with water and vacuum dried just like $\mathrm{Zn}$ (cur)O.

\subsection{Characterization}

Scanning electron microscopy (SEM) analysis was carried out using Tescan, Vega 3 LMU with Oxford EDX detector (Inca XmaW20) SEM. The sample was deposited on a carbon film for SEM analysis. The fluorescence image was recorded using a high sensitive STED confocal set up consisted of confocal microscope (Leica TCS SP5 STED, Leica Microsystem), APD detector and an argon laser with $430 \mathrm{~nm}$ excitation wavelength. $\mathrm{Zn}$ (cur)O was excited by a wavelength of $430 \mathrm{~nm}$ and typical emission wavelengths were 490-600 $\mathrm{nm}$. The $\mathrm{X}$-ray diffraction (XRD) data were recorded using a Bruker $\mathrm{d} 8$ discover $\mathrm{X}$-ray diffractometer equipped with $\mathrm{Cu}-\mathrm{K} \alpha$ radiation $(\lambda=1.5405 \AA)$. The monochromator used was Johansson type. The step size was $0.02 \mathrm{~s}$ and the scan rate was $20 \mathrm{~s}$ per step.

\subsection{Spectroscopic analysis}

The chemical structures of $\mathrm{Zn}$ (cur)O and, $\mathrm{ZnO}$ were characterized by FTIR spectroscopy. A Thermo Nicolet 4700 Fourier Transform Infrared Spectrometer equipped with a Class 1 laser was used for this purpose. The $\mathrm{KBr}$ pellet technique was applied to perform the transmission experiments in the range between 4000 and $400 \mathrm{~cm}^{-1}$. The absorption spectra were recorded at room temperature using a JASCO V-570 UV-VISNIR Spectrophotometer. Similarly, UV-visible diffuse reflectance spectra were measured using the same spectrophotometer in the range 200 to $800 \mathrm{~nm}$. The steady-state photoluminescence/fluorescence spectra were recorded at room temperature using Jobin-Yvon-Horiba Fluorolog III fluorometer and the FluorEssence program where the excitation and emission slits width were $5 \mathrm{~nm}$. The source of excitation was a $100 \mathrm{~W}$ xenon lamp, and the used detector was R928 operating at a voltage of $950 \mathrm{~V}$.

\subsection{Adsorption study}

For As(III) removal experiment, the same general procedure was followed for different concentrations of arsenic using samples of $\mathrm{Zn}$ (cur)O that differ by their curcumin content. Using $1 \mathrm{ppm}$ As(III) stock solution, $100 \mathrm{ppb}$ and 903 ppb arsenic concentrations were prepared in a final volume of $12 \mathrm{~mL}$. The $\mathrm{pH}$ of the solution was about 6 . After adding the $\mathrm{Zn}$ (cur)O, the arsenic solution was placed on the vortex (speed was no more than 1200 $\mathrm{rpm}$ ) and left shaking to disperse $\mathrm{Zn}$ (cur)O particles and ensure its good contact with the arsenic contamination. Based on the linear dynamic range indicated in the manual for arsenic measurements of the instrument used, we set a low and a high standard concentration of $7 \mathrm{ppb}$ and $55 \mathrm{ppb}$ respectively. With proper dilutions, the samples were set to a final maximum arsenic concentration of $50 \mathrm{ppb}$. Portions of $1 \mathrm{~mL}$ were withdrawn at different time intervals, and dumped directly into a $1 \mathrm{~mL}$ deionized water to obtain a final concentration of $50 \mathrm{ppb}$ as a maximum. For the high arsenic concentration (903 ppb), proper dilution was also done. After dilution, the samples were filtered using a general use filter paper. The experiments were done in duplicate or triplicate and each measurement was repeated twice. For each set of measurements done together (7-8 samples), a series of 6 or 8 standards were freshly prepared. Measurements of arsenic concentration were analyzed by SOLAAR atomic absorption spectrophotometer (Thermo Labsystems) with ASX-510 autosampler, G95 graphite furnace, FS95 furnace autosampler, PLATON Hg sampling, MILESTONE Ethos Plus microwave labstation, and SOLAAR data acquisition and analysis computer software. The percentage adsorption of arsenic on adsorbate from aqueous solution was calculated as follows:

$$
\text { Adsorption }(\%)=\left[\left(C_{\text {int }}-C_{\text {fin }}\right) / C_{\text {int }}\right] \times 100
$$

where $C_{\text {int }}$ and $C_{\text {fin }}$ are the initial and final arsenic concentrations in the solution, respectively.

\section{Results and discussion}

Briefly, $\mathrm{Zn}$ (cur)O nanoparticles were prepared through wet chemistry in which curcumin and zinc nitrate were mixed at $85-90{ }^{\circ} \mathrm{C}$ for 2 hours and the yellow colored solution was cooled to $0{ }^{\circ} \mathrm{C}$ in an ice bath, subsequently potassium hydroxide solution was added slowly. The yellowish precipitate obtained, $\mathrm{Zn}$ (cur)O, was centrifuged and washed. It should be noted that curcumin degrades in alkaline medium, ${ }^{\mathbf{4 6}}$ but addition of potassium hydroxide to curcumin and zinc nitrate did not show any appreciable degradation or change in colour of curcumin. $\mathrm{Zn}(x$ cur)O (where $x=0.5,1.0$, or 2.0 ) particles were synthesized respectively by using $0.5 \mathrm{mg}, 1.0 \mathrm{mg}$, or $2.0 \mathrm{mg}$ of curcumin. Washing of $\mathrm{Zn}$ (cur)O with acetone didn't alter its yellowish colour and no curcumin was detected in the wash solution. ZnO control was prepared without using curcumin.

The SEM images of the as synthesized $\mathrm{ZnO}$ and $\mathrm{Zn}$ (cur)O nanoparticles are presented in Fig. 1. The particles were of sizes ranging from 200-600 $\mathrm{nm}$ width and 600-2000 $\mathrm{nm}$ length. There were also particles of smaller sizes. The particles looked 
similar to grain or half grain. $\mathrm{Zn}$ (cur)O particles were found to be not different in their appearance and morphology compared to ZnO. Closer SEM images of these grain shaped Zn(cur)O were recorded in $200 \mathrm{~nm}$ resolution as shown in Fig. 2a, which shows that these grain appearing particles were assembled of nanosized particles. It should be noted that changing the concentration of curcumin $(0.5 \mathrm{mg}, 1.0 \mathrm{mg}$, or $2.0 \mathrm{mg})$ during preparation of $\mathrm{Zn}$ (cur)O did not have any foremost impact on the morphology of these particles, although $\mathrm{Zn}$ (cur)O prepared using $2 \mathrm{mg}$ curcumin were found to have more number of smaller or half-broken particles (Fig. 2b). The morphology of these particles was also clearly visible in fluorescence STED microscope (Fig. 3a). The fluorescence coming out from the whole region indicates curcumin is present all over the particle in $\mathrm{Zn}$ (cur)O. Amount of curcumin both on the surface and the inside of $\mathrm{ZnO}$ was estimated by thermogravimetric analysis. In between 100 and $700{ }^{\circ} \mathrm{C}$, the weight loss for naked $\mathrm{ZnO}$ was $\sim 4 \%$ and that of $\mathrm{Zn}$ (cur)O was $\sim 24 \%$. Based on these data the amount of curcumin in $\mathrm{Zn}$ (cur)O was estimated to be $\sim 20 \%$.

The XRD pattern of $\mathrm{ZnO}$ and $\mathrm{Zn}$ (cur)O is shown in Fig. $3 \mathrm{~b}$. All the $\mathrm{Zn}-\mathrm{O}$ hexagonal phase diffraction peaks were found at $2 \theta$ of $31.80^{\circ}(h k l, 100), 34.51^{\circ}(h k l, 002), 36.26^{\circ}(h k l, 101), 47.49^{\circ}(h$ $k l, 102), 56.61^{\circ}$ ( $\left.h k l, 110\right), 62.99^{\circ}$ ( $\left.h k l, 103\right), 66.55^{\circ}$ ( $\left.h k l, 200\right)$, $67.84^{\circ}(h k l, 112), 69.19^{\circ}(h k l, 201)$ and $77.53^{\circ}(h k l, 202)$. These observed peaks are in good agreement with those for hexagonal ZnO with wurtzite structure as reported earlier. ${ }^{47}$ The additional peaks found at $37.03^{\circ}, 37.80^{\circ}, 43.23^{\circ}$ and, $64.35^{\circ}$ were attributed to curcumin. The sharp diffraction peaks apparent in the figures indicate good crystallinity of the $\mathrm{ZnO}$ nanoparticles. No characteristic peaks of any other phase of $\mathrm{ZnO}$ or of any impurity were observed which indicates the relatively good purity of the compounds. The pattern of pure curcumin showed sharp characteristic peaks ${ }^{48}$ at $2 \theta$ of $20-30^{\circ}$. However, the characteristic peaks of curcumin were not observed when coated on $\mathrm{ZnO}$ in the XRD patterns of $\mathrm{Zn}(0.5$ cur $) \mathrm{O}$ and $\mathrm{Zn}$ (1.0cur)O, and only three peaks at 26.0, 26.8, and 29.45 for $\mathrm{Zn}$ (2.0cur)O were attributed to curcumin in this range. The Scherrer equation ${ }^{49}$ relates average crystallite size of the sample with the line broadening at full width at half maximum (FWHM) and thus the average crystallite sizes of samples were determined using the Scherrer equation:
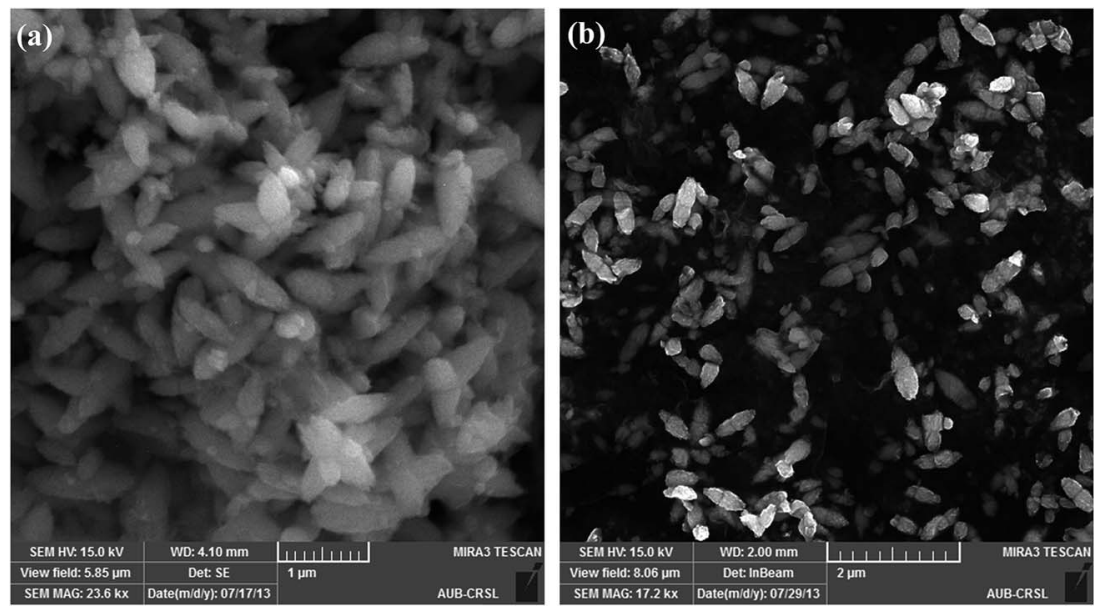

Fig. 1 SEM images of (a) $\mathrm{ZnO}$ and (b) curcumin doped $\mathrm{ZnO}$ which is termed as $\mathrm{Zn}$ (cur)O.
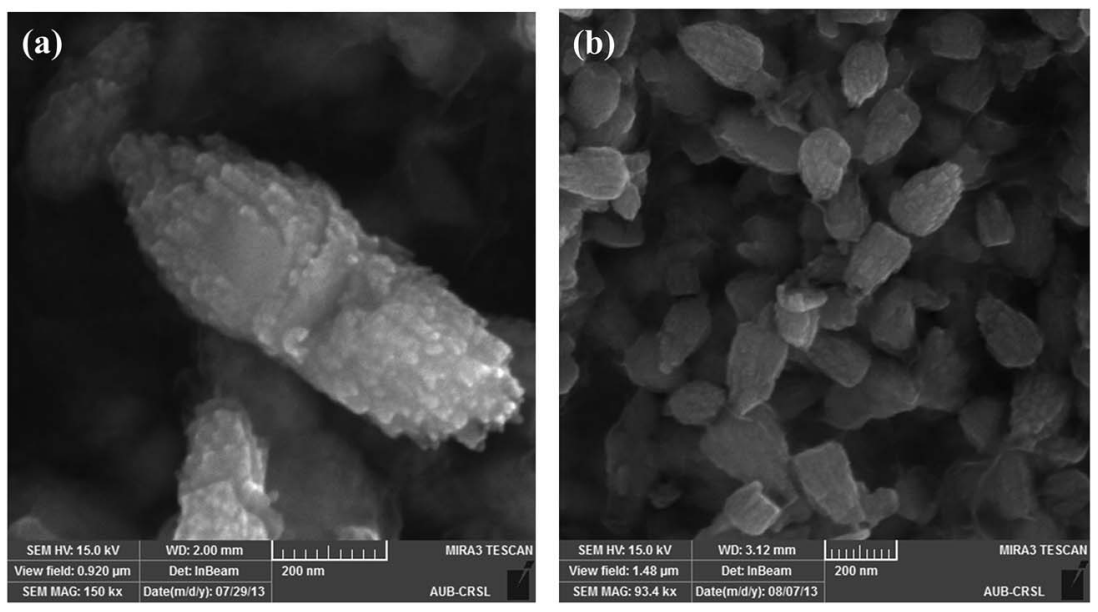

Fig. 2 SEM images of (a) $\mathrm{Zn}(0.5 \mathrm{cur}) \mathrm{O}$ where [cur] $=0.5 \mathrm{mg}$ and (b) $\mathrm{Zn}(2.0 \mathrm{cur}) \mathrm{O}$ where [cur] $=2.0 \mathrm{mg}$. 

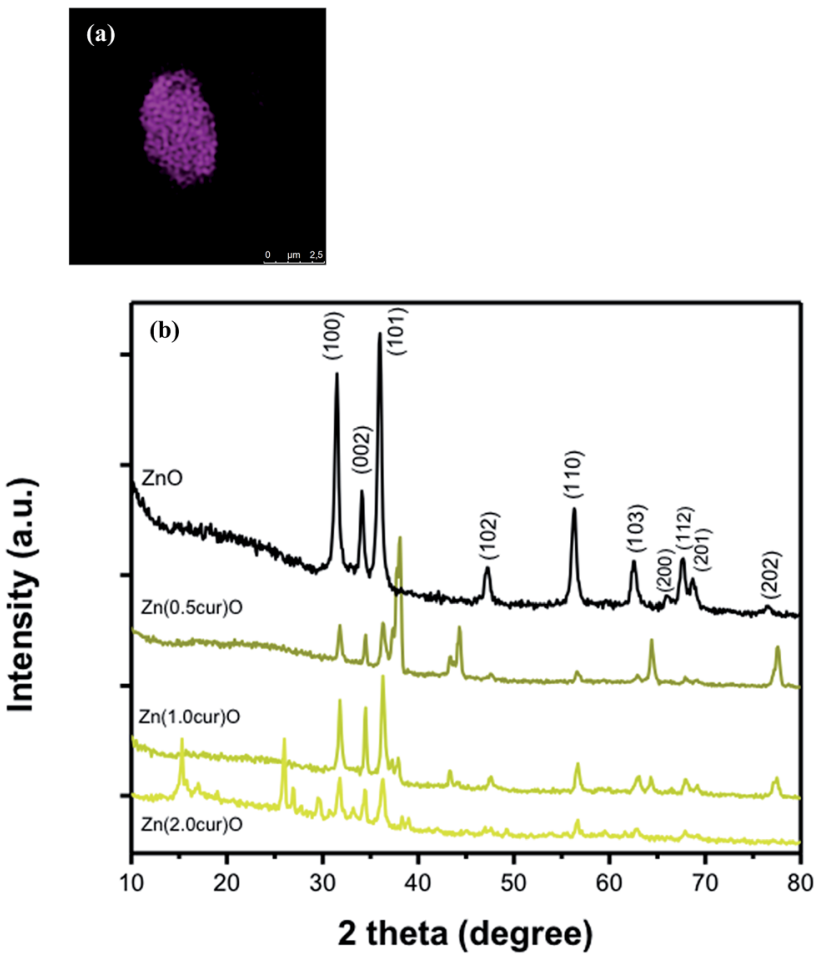

Fig. 3 (a) STED fluorescence image of $Z n(c u r) O$; (b) X-ray diffraction patterns of $\mathrm{ZnO}, \mathrm{Zn}(0.5$ cur $) \mathrm{O}, \mathrm{Zn}(1.0$ cur $) \mathrm{O}$ and $\mathrm{Zn}(2.0$ cur $) \mathrm{O}$ nanoparticles.

$$
D_{\mathrm{XRD}}=0.9 \lambda \beta / \cos \theta
$$

where $D_{\mathrm{XRD}}$ is the average crystallite sizes $(\mathrm{nm}), \lambda$ the X-ray wavelength $(\lambda=1.5406 \AA), \beta$ the full-width at FWHM of the highest intensity peak in radians, and $\theta$ the half of diffraction peak angle. The peak of the [100] plane (one of the strong peaks) was monitored to evaluate relative crystallite size with respect to curcumin concentration used during synthesis of $\mathrm{Zn}$ (cur)O. Crystallite sizes of $24.63 \mathrm{~nm}, 20.18 \mathrm{~nm}, 26.06 \mathrm{~nm}$, and $20.04 \mathrm{~nm}$ were obtained for $\mathrm{ZnO}, \mathrm{Zn}(0.5$ cur $) \mathrm{O}, \mathrm{Zn}(1.0$ cur $) \mathrm{O}$, and $\mathrm{Zn}(2.0$ cur $) \mathrm{O}$ respectively. This change is marginal without giving any specific relationship between crystalline structures and the amount of curcumin used in $\mathrm{Zn}$ (cur)O.

FTIR spectroscopy was done to inspect the interaction of curcumin with $\mathrm{ZnO}$ through the fingerprint vibrations of both curcumin and $\mathrm{ZnO}$ and of $\mathrm{Zn}$ (cur)O as shown in Fig. 4. Bare $\mathrm{ZnO}$ showed strong and broad absorption peak around $442 \mathrm{~cm}^{-1}$, which is the characteristic of $\mathrm{Zn}-\mathrm{O}$ bond..$^{50}$ No bands appeared around $3500 \mathrm{~cm}^{-1}$ nor at $1600 \mathrm{~cm}^{-1}$ which are usually attributed to $\mathrm{O}-\mathrm{H}$ stretching vibration peak of the hydroxyl functional group and to the bending vibration of the surface $\mathrm{H}-\mathrm{OH}$, which means that no hydroxyl groups adsorption on the surface of $\mathrm{ZnO}$ took place and what we had was $\mathrm{ZnO}$ rather than $\mathrm{Zn}(\mathrm{OH})_{2}$. The peak at $442 \mathrm{~cm}^{-1}$ in $\mathrm{ZnO}$ shifted to $484 \mathrm{~cm}^{-1}$ in $\mathrm{Zn}$ (cur)O and was less pronounced suggesting the presence of an altered $\mathrm{Zn}-\mathrm{O}$ bond due to its interaction with curcumin.

The frequency region of both phenolic $\nu(\mathrm{OH})$ vibrations of the curcumin was computed to be at $3595 \mathrm{~cm}^{-1}$, but was shifted to lower frequency at $3510 \mathrm{~cm}^{-1}$ due to intramolecular and intermolecular $\mathrm{H}$-bonding in curcumin..$^{51}$ In $\mathrm{Zn}$ (cur)O the location of the band shifted to $3430 \mathrm{~cm}^{-1}$ indicating interaction of these phenolic hydroxyls with ZnO. Curcumin molecule has one of the most prominent functional group-the $\beta$-diketone group-at the center, which has high driving force to form chelation with metal ions. ${ }^{40,42}$ The $\beta$ diketo system in curcumin was found to form charge transfer complexes with $\mathrm{TiO}_{2}$ nanoparticles. ${ }^{52}$ Khalil et al. have suggested a four coordination zinccurcumin complex through $\beta$ diketo system based on mass spectral data. ${ }^{42}$ This could be due to the co-existence of keto and enol groups in curcumin molecules. In this respect, it is not surprising to have an interaction-be it weak or strong-of this $\beta$-diketone moiety with $\mathrm{Zn}$ atom at the bulk surface of $\mathrm{ZnO}$. In fact, the curcumin spectra did not show any peak in the carbonyl region $\left(1800-1650 \mathrm{~cm}^{-1}\right)$ as reported earlier, neither in the solid state nor in solutions, indicating that curcumin exists mainly in the enol form. However, two peaks were obtained in this region at $\sim 1650 \mathrm{~cm}^{-1}$ and at $1756 \mathrm{~cm}^{-1}$ for the $\mathrm{ZnO}-$ curcumin compound, where the $1650 \mathrm{~cm}^{-1}$ peak could be due to $\nu(\mathrm{C}=\mathrm{O})$ of curcumin. The other peak at $1756 \mathrm{~cm}^{-1}$ could be related to the carbonyl's asymmetric mode of vibration in its diketo solid form (the symmetric mode is unseen usually because its intensity is too low). Theoretical calculations show that the enolic $\nu(\mathrm{OH})$ mode is at $2979 \mathrm{~cm}^{-1} .{ }^{51}$ Experimentally, this band usually appears weak and broad as it did in this case. The absence of a clearly defined $\nu(\mathrm{OH})$ band has been previously discussed by Tayyari et al. ${ }^{53}$ stating that "the intensity and broadness of the enol band is dependent on the strength of the intramolecular hydrogen bond where it would decrease in intensity and increase in broadness as the strength of the hydrogen bond increases". Also in their work on dibenzoylmethane, a $\beta$-diketone system, similar to curcumin, they have suggested that the $\pi$-systems, such as the phenyl groups increase the H-bond strength through conjugation with the enol ring. The hydroxyl and methoxy groups on the phenyl rings of curcumin are electron donating systems expected to even cause stronger hydrogen bond effect. So any weakening of these groups' electronegativity (phenyl ring and/or the existing methoxy and hydroxy groups on it) by forming bonds or conjugating with other moieties would cause the hydrogen bond strength to decrease thus allowing the enol peak to appear more clearly. In our Raman spectroscopic measurement the Raman band at $1601 \mathrm{~cm}^{-1}$ was obtained for curcumin due to aromatic vibration $\nu_{\mathrm{C}=\mathrm{C} \text { ring }}$ and this band shifted to $1593 \mathrm{~cm}^{-1}$ in $\mathrm{Zn}$ (cur)O. Therefore, one of the possibilities does not rule out involvement of the $\mathrm{ZnO}$ with the hydroxyl or methoxy groups on the phenyl ring.

However, the prominent enol peak could also be due to chelation of curcumin with metal ions as suggested earlier for zinc-curcumin complex..$^{42}$ In our FT-IR measurement, the peak in curcumin at $\sim 1630 \mathrm{~cm}^{-1}$ has a predominantly mixed $\nu(\mathrm{C}=\mathrm{C})$ and $\nu(\mathrm{C}=\mathrm{O})$ character. The most prominent band in the curcumin spectrum was found at $1510 \mathrm{~cm}^{-1}$ attributed to highly mixed vibrations of $\nu(\mathrm{C}=\mathrm{O}), \delta(\mathrm{CC}=\mathrm{O})$, and $\delta(\mathrm{CCC}) .{ }^{51}$ The IR bands in frequency region $1430-1460 \mathrm{~cm}^{-1}$ are due to deformation vibrations of the two methyl groups. Most bands in 


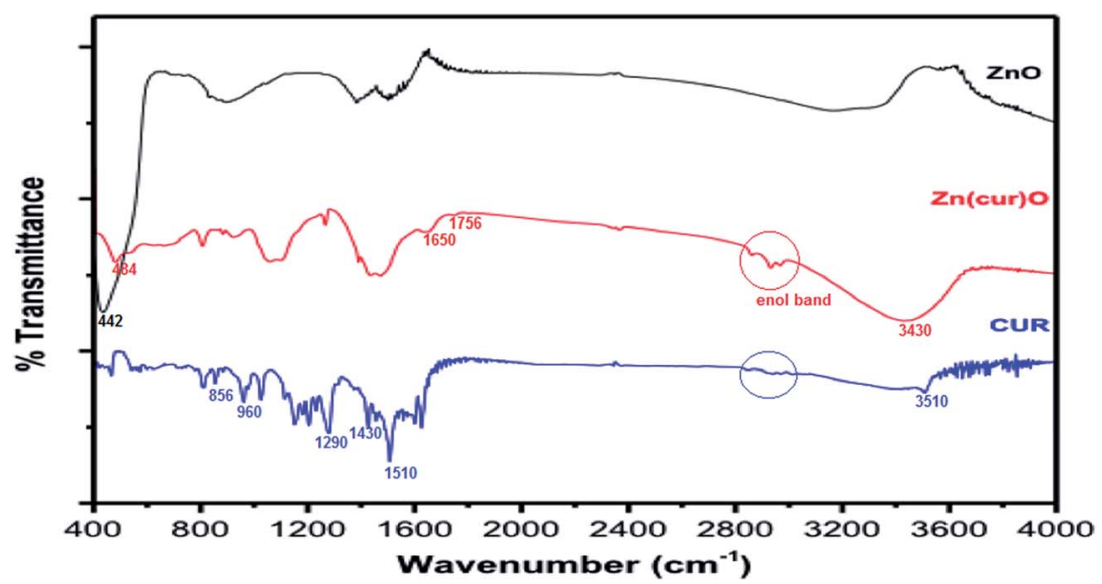

Fig. 4 FTIR spectra of as-synthesized $\mathrm{ZnO}$, curcumin, and $\mathrm{Zn}(1.0 \mathrm{cur}) \mathrm{O}$ nanostructures at room temperature.

frequency region $1450-1300 \mathrm{~cm}^{-1}$ are highly mixed. Similarly, the Raman shift at $1626 \mathrm{~cm}^{-1}$ was found for curcumin, which is due to $\nu_{\mathrm{C}=\mathrm{C}}$ and $\nu_{\mathrm{C}=\mathrm{O}}$ of curcumin and similar to reported experimental value and close to computed values $1630 \mathrm{~cm}^{-1}$ and $1615 \mathrm{~cm}^{-1}$ respectively. ${ }^{51} \mathrm{In} \mathrm{Zn}$ (cur)O this band shifted up field to $1630 \mathrm{~cm}^{-1}$ indicative of a relatively strong coordination of the carbonyl moiety. ${ }^{54}$ The Raman band at $1314 \mathrm{~cm}^{-1}$ is due to $\delta_{\text {PhCCHOHenol }}$. The Raman peak at $1304 \mathrm{~cm}^{-1}$ for $\delta_{\mathrm{COHenol}}$ was not found in curcumin, but was observed for $\mathrm{Zn}$ (cur)O. The band at $1248 \mathrm{~cm}^{-1}$ due to $\delta_{\mathrm{COHenol}}$ of curcumin also shifted to around $1224 \mathrm{~cm}^{-1}$ in $\mathrm{Zn}$ (cur)O indicating presence of CO type bond associating with zinc. The carbonyl and hydroxyl groups of curcumin can form chelate with zinc. This could also be supported by the disappearance and shifting of the IR bands at 960 and $855 \mathrm{~cm}^{-1}$ in $\mathrm{Zn}$ (cur)O (see Fig. 4), which are attributed to $\nu(\mathrm{C}-\mathrm{O})$ vibrations. Present spectroscopic analysis supports that curcumin chelates with zinc through enol form but at the same time a weak link between hydroxyl or methoxy groups on the phenyl ring and $\mathrm{ZnO}$ exists.

UV-Vis diffused reflectance spectra of the $\mathrm{Zn}(\mathrm{cur}) \mathrm{O}$ and $\mathrm{ZnO}$ are depicted in Fig. 5. All of them show a similar broad and strong absorption spectrum with an onset at $400 \mathrm{~nm}$ and a maximum at about $343 \mathrm{~nm}$, which is characteristic of $\mathrm{ZnO}$ wide-band semiconductor. For $\mathrm{Zn}($ cur $) \mathrm{O}$, another strong absorption maximum was found at around $445 \mathrm{~nm}$ with an absorption onset at $\sim 570 \mathrm{~nm}$ for $\mathrm{Zn}$ (cur)O confirming the presence of curcumin. As seen for curcumin in ethanol, the position of the curcumin peak in $\mathrm{Zn}$ (cur)O is red shifted compared to curcumin in solution. This shift in absorption spectra could be due to the interaction of curcumin with zinc ion that decreases the band gap between $\pi-\pi^{*}$ electronic transition of curcumin.

The photoluminescence (PL)/fluorescence of $\mathrm{Zn}(\mathrm{cur}) \mathrm{O}$ and $\mathrm{ZnO}$ were measured at two excitation wavelengths: $320 \mathrm{~nm}$ (for ZnO excitation), and $425 \mathrm{~nm}$ (for curcumin excitation) in water and compared in Fig. 6. At $320 \mathrm{~nm}$ excitation wavelength (see Fig. 6a), ZnO showed two emission bands, one in the UV range at around $358 \mathrm{~nm}$, which is associated with exciton emission,

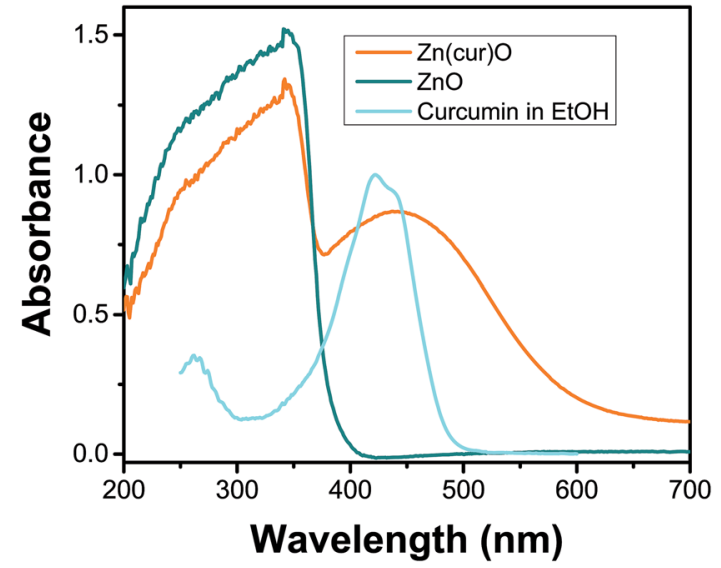

Fig. 5 UV-visible diffuse reflectance spectra of as-synthesized $\mathrm{ZnO}$, and $\mathrm{Zn}(1.0$ cur $) \mathrm{O}$ nanostructures at room temperature. UV-visible absorption spectrum of curcumin in ethanol is shown for comparison.

another in the visible range at around $560 \mathrm{~nm}$, which originates from electron-hole (e-h) recombination at the deep level caused by oxygen vacancy or zinc interstitial defects. ${ }^{55}$ This result - the observation of a visible PL in water - by itself is unconventional and interesting given the fact that even small amounts of water would kill ZnO PL - namely visible fluorescence - as hydroxyl groups coordinate on the surface of $\mathrm{ZnO}$ nanoparticles. Curcumin usually shows fluorescence in this region (around $530 \mathrm{~nm}$ ), ${ }^{33}$ however its contribution in $\mathrm{Zn}($ cur)O was minimum or negligible. The visible photoluminescence in $\mathrm{Zn}$ (cur)O reduced by $\sim 10$ folds compared to naked ZnO. Similar quenching of visible emission has been observed and reported for capped $\mathrm{ZnO}$ compared with the uncapped $\mathrm{ZnO} .^{55}$ Interestingly, in comparison to $\mathrm{ZnO}$, the $\mathrm{UV}$ emission of $\mathrm{Zn}$ (cur)O at 358 $\mathrm{nm}$ increased by $\sim 4$ fold. This trend has been related earlier to increased crystallinity and decreased surface defects. ${ }^{56}$ Some polymer and/or organic ligands are thought to fill up (passivate) the defects on ZnO surface, which act as visible luminescence centers, resulting in quenching the $\mathrm{ZnO}$ visible emission and 

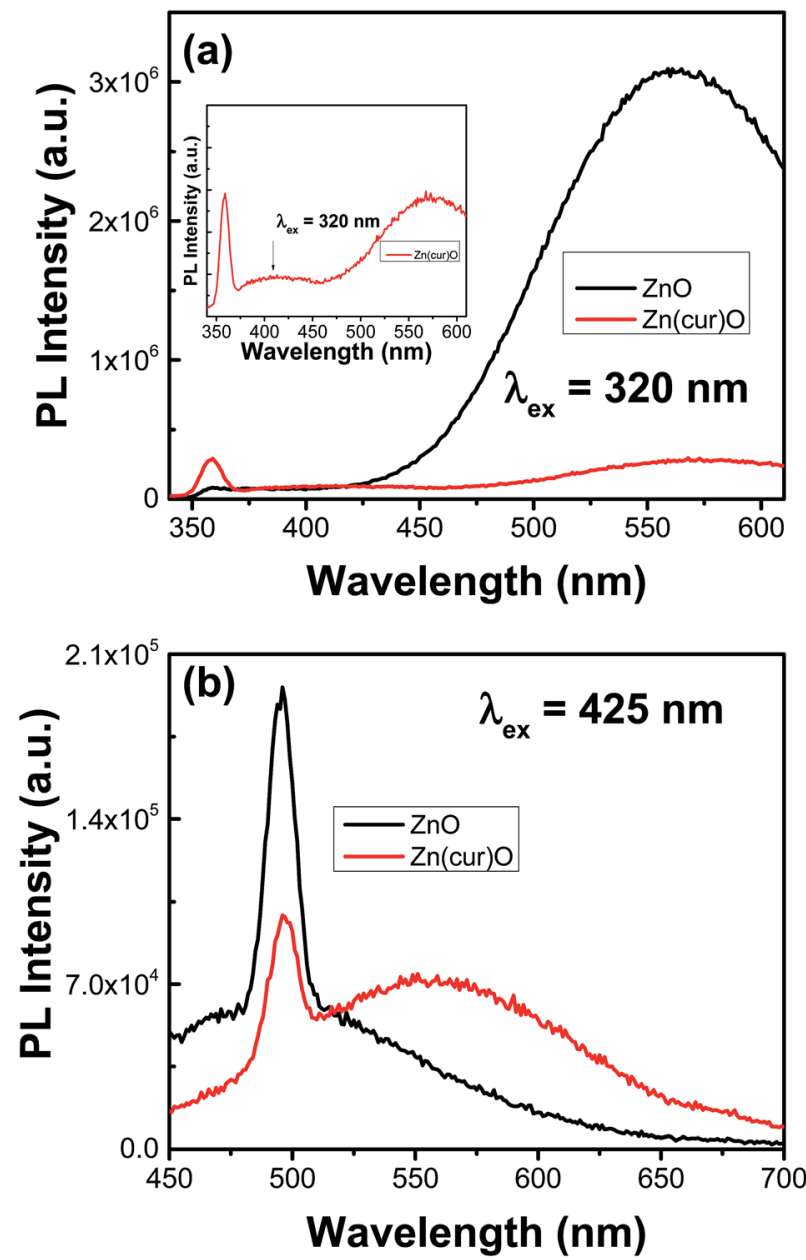

Fig. 6 Photoluminescence/fluorescence spectra of as-synthesized $\mathrm{ZnO}$, and $\mathrm{Zn}(1.0 \mathrm{cur}) \mathrm{O}$ nanostructures in water.

improving the UV emission. ${ }^{55}$ This is what we think curcumin is doing. It is important to point out that the visible emission from $\mathrm{ZnO}$ cannot be fully explained by a single type of defect. ${ }^{57}$ The visible emission band of $\mathrm{Zn}$ (cur)O was found to be $10 \mathrm{~nm}$ red shifted compared to that of $\mathrm{ZnO}$. $\mathrm{Zn}$ (cur)O gave an additional band at around $405 \mathrm{~nm}$ (see inset of Fig. 6a) that was absent in $\mathrm{ZnO}$. The emission line at $405 \mathrm{~nm}$ could be also related to defect emission caused by curcumin because we don't see any such peak in ZnO. At excitation wavelength of $425 \mathrm{~nm}$ (Fig. 6b), ZnO is not expected to have a good photoluminescence behavior due to poor light absorption in contrast to $\mathrm{Zn}$ (cur)O, which has a strong light absorption at this wavelength due to curcumin. Thus, the contribution of fluorescence of $\mathrm{Zn}$ (cur)O relative to $\mathrm{ZnO}$ is substantial at this excitation wavelength and the emission is largely due to curcumin rather than $\mathrm{ZnO}$, as seen for curcumin alone in water at $\sim 530 \mathrm{~nm} .{ }^{33}$ The peak at $495 \mathrm{~nm}$ in both the cases was due to scattering.

Subsequently, we tested photoluminescence behavior of $\mathrm{ZnO}$ and $\mathrm{Zn}$ (cur)O for the determination of arsenic. The sensing of arsenic was done for two concentration ranges: from 0 to 1000 $\mathrm{ppb}(1 \mathrm{ppm})$ and from $1 \mathrm{ppm}$ to $10 \mathrm{ppm}$; thus, stock solutions of respectively $3000 \mathrm{ppb}$ and $30 \mathrm{ppm}$ of arsenic in water were used for this purpose. ZnO didn't show any systematic photoluminescence alteration in both the ranges of arsenic concentrations used at excitation wavelengths $280 \mathrm{~nm}$ and $425 \mathrm{~nm}$ (not shown), which limit use of $\mathrm{ZnO}$ to sense arsenic. However, $\mathrm{Zn}$ (cur)O showed an enhancement in fluorescence intensity with increasing arsenic concentration from 1 to $10 \mathrm{ppm}$ as presented in Fig. 7. The binding mode of arsenic with $\mathrm{ZnO}$ surfaces has been experimentally established earlier, ${ }^{58}$ it has been found that surface absorption is the main cause of As(III) binding on $\mathrm{ZnO}$ surface. In the present case surface adsorption of As(III) on $\mathrm{Zn}-\mathrm{O}$ surfaces facilitate As(III) to come near to curcumin present in $\mathrm{Zn}$ (cur)O surfaces and interact on the phenyl rings and/or the hydroxyls groups as proposed subsequently. The enhancement of fluorescence could be linked with absorption of arsenic with $\mathrm{Zn}$ (cur)O surfaces. After removing arsenic from the $\mathrm{Zn}$ (cur)O surfaces, the same materials can be reused.

To comprehend effect of curcumin concentration in $\mathrm{Zn}$ (cur) $\mathrm{O}$, a comparison was made for response for $\mathrm{Zn}(1.0$ cur $) \mathrm{O}$ and $\mathrm{Zn}$ (2.0cur)O as depicted in Fig. $8 \mathrm{a}$ in the concentration rage 0 to $1000 \mathrm{ppb}$ and both of them showed good linear change in fluorescence signal. The higher sensitivity for $\mathrm{Zn}(2.0$ cur $) \mathrm{O}$ is due to higher fluorescence of $\mathrm{Zn}(2.0 \mathrm{cur}) \mathrm{O}$ compared to $\mathrm{Zn}$ (1.0cur)O because of more curcumin content in $\mathrm{Zn}$ (2.0cur)O. Further, $\mathrm{Zn}(2.0 \mathrm{cur}) \mathrm{O}$ was chosen because of higher sensitivity and the response was extended up to $10000 \mathrm{ppb}$ (10 ppm) using $\mathrm{Zn}$ (2.0cur)O as fluorescence probe for sensing application. As shown in Fig. 8b the fluorescence response showed an exponential increase and at higher concentration it started saturating. From Fig. 8b it can be estimated that the linear changes for sensing application is valid till around $3000 \mathrm{ppb}$ of arsenic, where the present method could be applicable to determine arsenic in water samples. The detection limit estimated was $100 \mathrm{ppb}$.

The potential application of the curcumin doped $\mathrm{ZnO}$ system for arsenic removal was established in comparison with naked $\mathrm{ZnO}$. The same general procedure was followed for different concentrations of arsenic, mainly 100 and 903 ppb, using samples of $\mathrm{Zn}$ (cur)O that differ by their curcumin content. Briefly, a stock of $200 \mathrm{ppm} \mathrm{Zn}$ (cur)O (and $\mathrm{ZnO}$ ) solution was

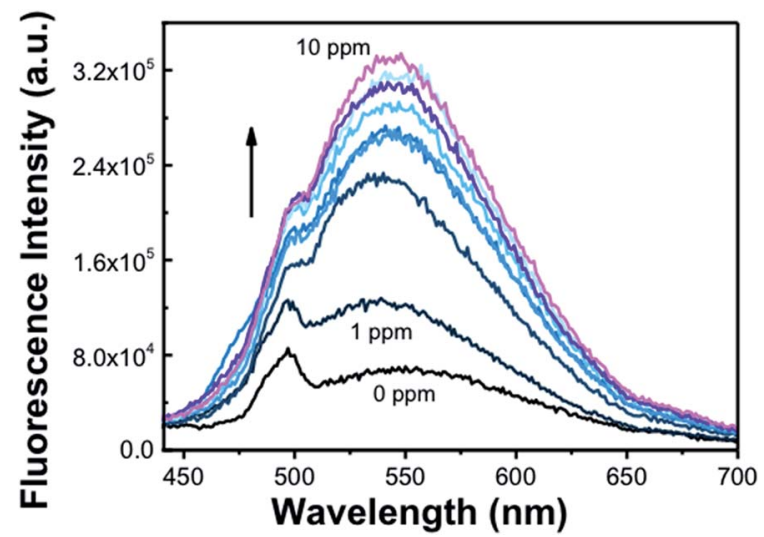

Fig. 7 Fluorescence sensing of arsenic in the concentration range 1 to 10 ppm using $\mathrm{Zn}(1.0$ cur $) \mathrm{O}$. 

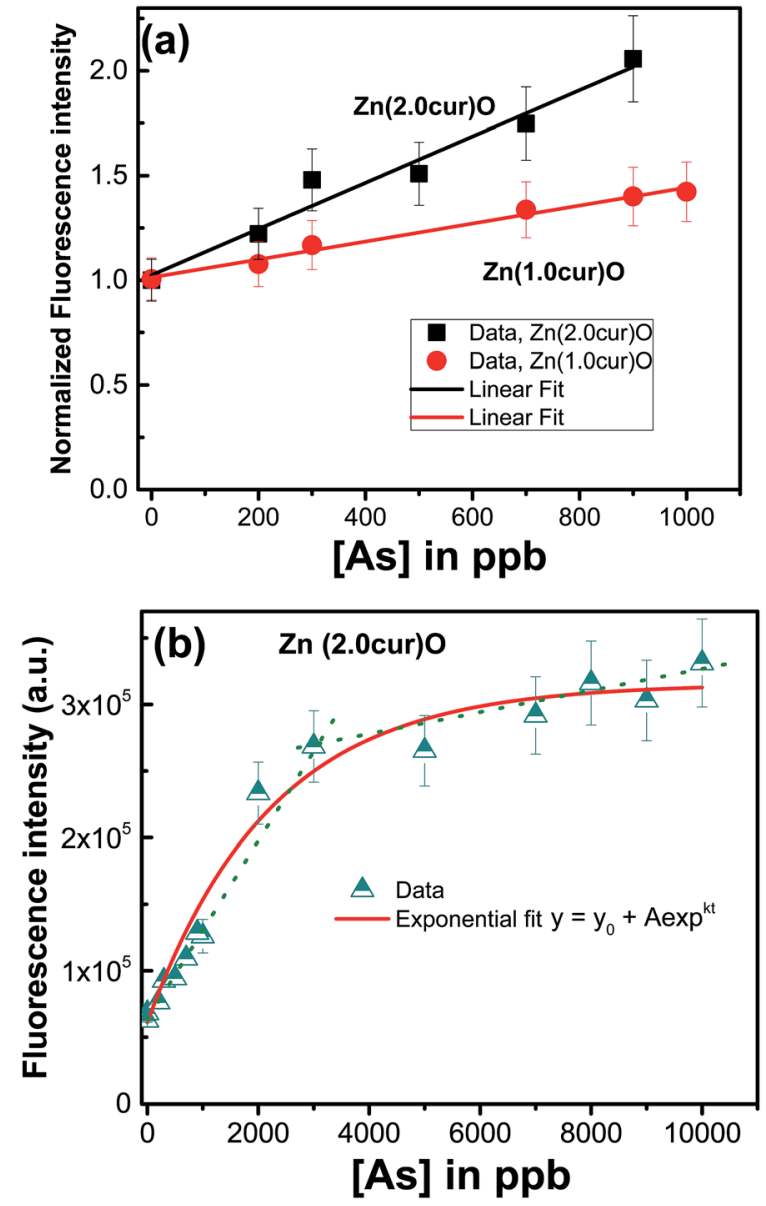

Fig. 8 (a) Fluorescence intensity response of $\mathrm{Zn}(1.0 \mathrm{cur}) \mathrm{O}$ and $\mathrm{Zn}(2.0$ cur $) \mathrm{O}$ in the arsenic concentration range 0 to $100 \mathrm{ppm}$. (b) Fluorescence intensity response of $\mathrm{Zn}(2.0$ cur)O in the arsenic concentration range 1 to $10000 \mathrm{ppb}$. The excitation wavelength used was $425 \mathrm{~nm}$ and emission wavelength was $550 \mathrm{~nm}$.

prepared by mixing $1 \mathrm{mg}$ of the compound in $5 \mathrm{~mL}$ deionized water. A secondary stock of $1 \mathrm{ppm}$ of arsenic was prepared from a primary stock, $\mathrm{As}_{2} \mathrm{O}_{3} \mathrm{As}(\mathrm{III})$ oxide, $1000 \mathrm{ppm}$. The stock solution was diluted to two initial As(III) concentrations, $903 \mu \mathrm{g} \mathrm{L}^{-1}$ and $100 \mu \mathrm{g} \mathrm{L}^{-1}$ (as $903.2 \mu \mathrm{g} \mathrm{L}^{-1}$ falls in the high range of arsenic specie concentration found in natural water around the world, and $97.8 \mu \mathrm{g} \mathrm{L}^{-1}$ is in the middle to low range $\left.{ }^{59}\right)$. For removal and adsorption study, arsenic was estimated by atomic absorption spectrophotometer. When the initial As(III) concentration was 100 ppb (see Fig. 9a), it was found that in just 30 minutes $\sim 85$, $\sim 93.6$, and $\sim 90 \%$ of $\mathrm{As}(\mathrm{III})$ in the water sample could be removed with $\mathrm{Zn}(0.5 \mathrm{cur}) \mathrm{O}, \mathrm{Zn}(1.0 \mathrm{cur}) \mathrm{O}$, and $\mathrm{Zn}(2.0 \mathrm{cur}) \mathrm{O}$ respectively, leaving arsenic concentrations below maximum contaminant level (MCL) [7.865, 3.0845, and 4.679 respectively]. After 3 hours, the equilibrium As(III) concentration in the water sample was less than $5 \mathrm{ppb}$ after the treatment, which meets the EPA standard for arsenic in drinking water. $\mathrm{Zn}(1.0 \mathrm{cur}) \mathrm{O}$ removed As(III) almost completely ([As $\left.]_{180 \mathrm{~min}}=0.933 \mathrm{ppb}\right)$ with the highest adsorption percent (98\%) followed by $\mathrm{Zn}(2.0 \mathrm{cur}) \mathrm{O}$ (96\%) and $\mathrm{Zn}(0.5$ cur)O (92\%). Bare $\mathrm{ZnO}$ removed $\sim 52 \%$ of the initial arsenic concentration after half an hour $\left([\mathrm{As}]_{60 \text { min }} \sim 20\right.$ $\mathrm{ppb})$ and $\sim 72 \%$ after 3 hours ([As $\left.]_{180 \text { min }} \sim 14.6 \mathrm{ppb}\right)$ failing to take arsenic down its MCL. When the initial As(III) concentration was $903 \mathrm{ppb} \sim 71$ and $67 \%$ of As(III) could be removed with $\mathrm{Zn}$ (1.0cur)O and $\mathrm{Zn}(2.0$ cur)O respectively in $30 \mathrm{~min}$ (see Fig. 9b).

Even for such a high As(III) concentration, curcumin doped ZnO nanostructures demonstrated an excellent removal effect given the low loading of $42 \mathrm{ppb}\left(0.04 \mathrm{~g} \mathrm{~L}^{-1}\right)$. As(III) equilibrium concentrations of about $180 \mathrm{ppb}$ were left after the treatment period of 3 hours achieving almost similar $\sim 75 \%$ removal for both curcumin contents. Therefore, highly efficient As(III) removal is possible with these curcumin doped $\mathrm{ZnO}$ sub-microgranules requiring no pre-treatment (oxidation and/or $\mathrm{pH}$ adjustment) and post treatment $\mathrm{pH}$ adjustment. It is expected that doubling or tripling the loading amount will remove the 903 ppb arsenic contamination completely; even then the material loading is still considered economical.

To investigate the mechanism of As adsorption, the Lagergren pseudo first-order and Lagergren pseudo second-order equations were used to test the experimental data of different curcumin content in the $\mathrm{Zn}$ (cur)O adsorbent. The linearized pseudo-first-order equation can be presented as: ${ }^{\mathbf{6 0}}$
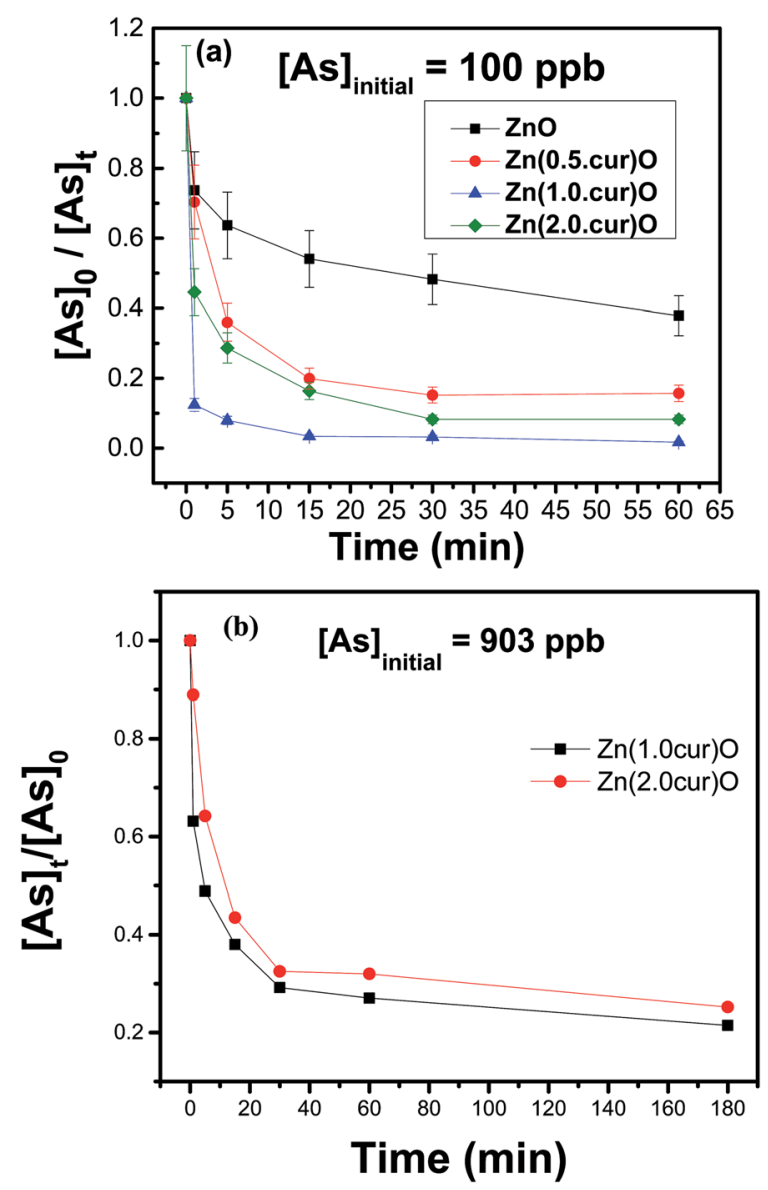

Fig. 9 Adsorption kinetics of As(III) on $\mathrm{Zn}(x \mathrm{cur}) \mathrm{O}$ and $\mathrm{ZnO}$ : (a) initial As(III) concentration was $100 \mu \mathrm{g} \mathrm{L}^{-1}$ and (b) initial As(III) concentration was $903 \mu \mathrm{g} \mathrm{L}{ }^{-1}$, the error margin was within $10 \%$. 


$$
\ln \left(q_{\mathrm{e}}-q_{t}\right)=-k_{1} t+\ln q_{\mathrm{e}}
$$

where $q_{\mathrm{e}}$ and $q_{t}$ are the capacities $\left(\mathrm{mg} \mathrm{g}^{-1}\right)$ of arsenic adsorbed at equilibrium and at time $t$, respectively, and $k_{1}$ is the pseudofirst-order rate adsorption constant $\left(\mathrm{mg} \mathrm{g}^{-1} \mathrm{~min}^{-1}\right)$. Plot of $\ln \left(q_{\mathrm{e}}\right.$ $-q_{t}$ ) versus $t$ for an adsorbent yielded a straight line, usually governing the first 20-30 minutes of interaction, but the correlation coefficients $(R)$ was poorer as shown in Fig. 10a and b. The rate constant was found to be dependent on the initial concentration of the adsorbate and varying greatly depending on the adsorption system.

The linearized pseudo-second-order equation is given as:

$$
t / q_{t}=t / q_{\mathrm{e}}+1 /\left(k_{2} q_{\mathrm{e}}{ }^{2}\right)
$$

$k_{2}$ is the pseudo-second-order rate constant and it depends on the operating conditions, such as initial $\mathrm{pH}$ and solution concentration, temperature, agitation rate, etc. ${ }^{60}$ (all these parameters were kept constant for all the experiments). $k_{2}$ would decrease as the initial solution concentration increase as it takes a longer time to reach equilibrium. If the adsorption system follows a pseudo-second-order kinetics, then a plot of $t$ / $q_{t}$ versus $t$ would be linear and $k_{2}$ and $q_{\mathrm{e}}$ can be determined from the intercept and slope of the graph eqn (2). In our case, the kinetic study results could be best fitted into a pseudo secondorder rate kinetic model as demonstrated in Fig. 10c and d. The kinetic parameters obtained in fitting the experimental data are summarized in Tables 1 and 2. The applicability of the pseudosecond-order rate model was evaluated by the square of the correlation coefficient $R\left(R^{2}\right)$, and its closeness to 1 indicates that the model fits the experimental data accurately. The correlation coefficients for the second-order kinetic model were greater than 0.999 for all the fits, which is better than first-order kinetic model (Fig. 10a and b). The sorption capacity of adsorbent was calculated by:

$$
q_{\mathrm{e}}=V\left(C_{\mathrm{o}}-C_{\mathrm{e}}\right) / m
$$

where $C_{\mathrm{o}}$ and $C_{\mathrm{e}}$ are the initial and equilibrium concentration $\left(\mathrm{mg} \mathrm{L}^{-1}\right)$ respectively, $m$ is the mass of dry carbon sample used (g) and $V$ volume of solution (mL). The calculated $q_{\mathrm{e}}$ values also agree very well with the experimental $q_{\mathrm{e}}$.

Due to the differences in the experimental conditions, it is not possible to directly compare the adsorption efficiency among reports in literature. However, a rough comparison can be made. For instance, concerning relatively high arsenic concentrations, Yang and co-workers ${ }^{59}$ synthesized ZnO microtubes, which have a large specific surface area. In their study,
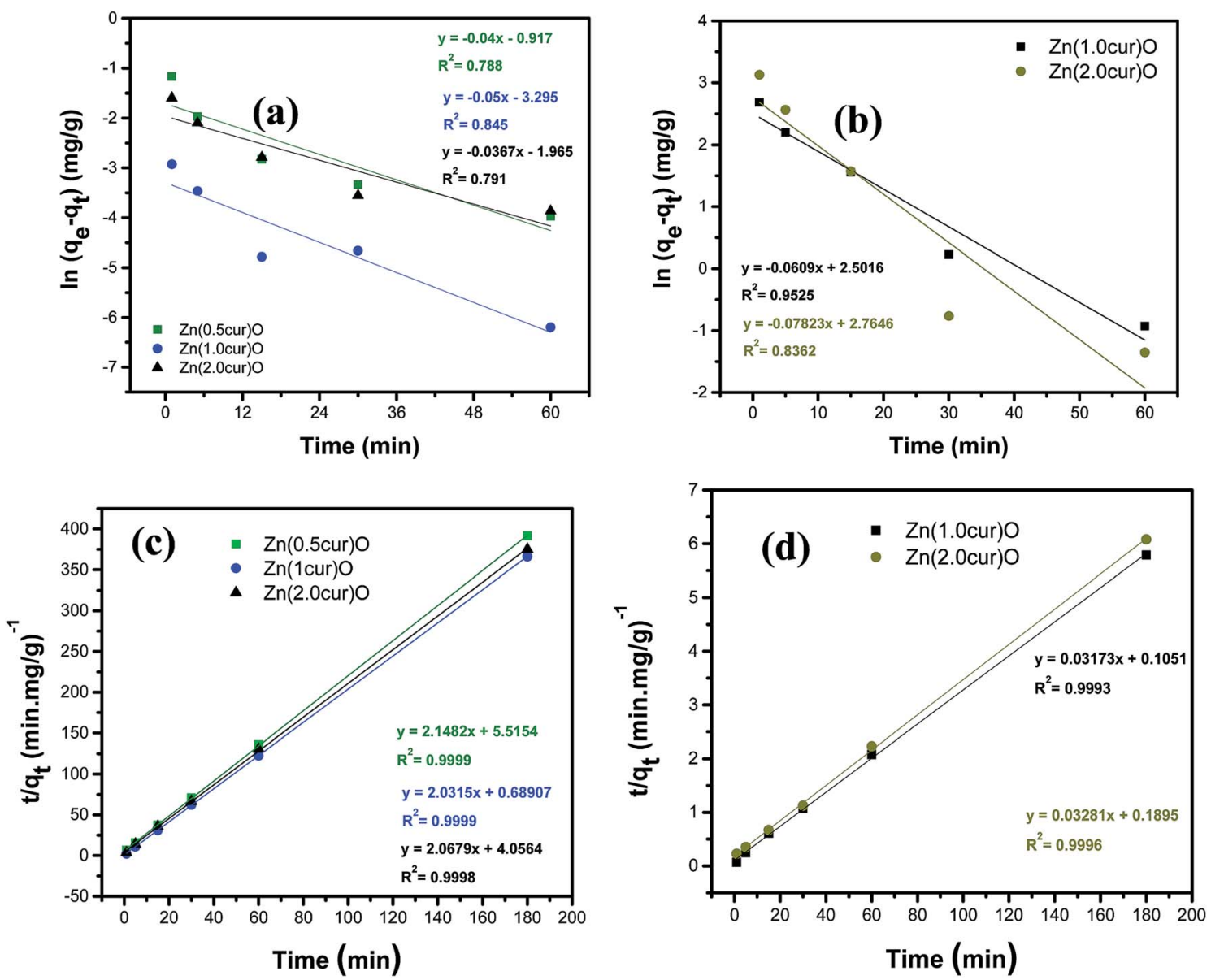

Fig. 10 (a) and (b) are pseudo-first-order rate kinetic model fitting of the adsorption kinetics studies demonstrated in Fig. 9a and b, respectively. (c) and (d) are pseudo-second-order rate kinetic model fitting of the adsorption kinetics studies demonstrated in Fig. 9a and b, respectively. 
Table 1 Kinetic parameters of $\mathrm{Zn}(x \mathrm{cur}) \mathrm{O}$ nanostructures adsorption on As(III) at initial concentrations of $100 \mathrm{ppb}$

\begin{tabular}{lllll}
\hline & $\begin{array}{l}q_{\mathrm{e}(\mathrm{cal})} \\
\left(\mathrm{mg} \mathrm{g}^{-1}\right)\end{array}$ & $\begin{array}{l}q_{\mathrm{e}(\exp )} \\
\left(\mathrm{mg} \mathrm{g}^{-1}\right)\end{array}$ & $\begin{array}{l}K_{\mathrm{ad}} \\
\left(\mathrm{mg}^{-1} \mathrm{~g} \mathrm{~min}^{-1}\right)\end{array}$ & $R^{2}$ \\
\hline Zn(0.5cur)O & 0.4655 & 0.45972 & 0.8367 & 0.9999 \\
Zn(1.0cur)O & 0.4922 & 0.49146 & 5.9892 & 0.9999 \\
Zn(2.0cur)O & 0.4836 & 0.479645 & 1.0542 & 0.9996
\end{tabular}

Table 2 Kinetic parameters of $\mathrm{Zn}(x c u r) O$ nanostructures adsorption on As(III) at initial concentrations of $903 \mathrm{ppb}$

\begin{tabular}{lllll}
\hline & $\begin{array}{l}q_{\mathrm{e}(\mathrm{cal})} \\
\left(\mathrm{mg} \mathrm{g}^{-1}\right)\end{array}$ & $\begin{array}{l}q_{\mathrm{e}(\exp )} \\
\left(\mathrm{mg} \mathrm{g}^{-1}\right)\end{array}$ & $\begin{array}{l}K_{\mathrm{ad}} \\
\left(\mathrm{mg} \mathrm{g}^{-1} \mathrm{~min}^{-1}\right)\end{array}$ & $R^{2}$ \\
\hline $\mathrm{Zn}(1.0$ cur $) \mathrm{O}$ & 31.5160 & 29.2821 & 0.009579 & 0.9993 \\
$\mathrm{Zn}(2.0$ cur)O & 30.4785 & 27.177 & 0.005681 & 0.9996 \\
\hline
\end{tabular}

the initial As(III) solution concentration was $0.9032 \mathrm{mg} \mathrm{L}^{-1}, \mathrm{pH}$ value at 7.0, and the amount of $\mathrm{ZnO}$ loading at $0.08 \mathrm{~g} \mathrm{~L}^{-1}$, the $K_{\text {ad }}$ was determined at $0.005 \mathrm{mg}^{-1} \mathrm{~g} \mathrm{~min}{ }^{-1}$; it increased to $0.015 \mathrm{mg}^{-1} \mathrm{~g} \mathrm{~min}^{-1}$ upon loading with $0.1 \mathrm{~g} \mathrm{~L}^{-1}$. In our study, having the same initial As(III) concentration, $\mathrm{pH}$ value at 6, and much lower adsorbent loading of $43 \mu \mathrm{g} \mathrm{L}^{-1}$, the $K_{\text {ad }}$ was determined to be higher $\left(0.0096\right.$ and $0.0057 \mathrm{mg}^{-1} \mathrm{~g} \mathrm{~min}{ }^{-1}$ for $\mathrm{Zn}(1.0$ cur)O and $\mathrm{Zn}$ (2.0cur)O respectively) (see Table 2). For the low arsenic concentration range, the aforementioned study obtained $0.007 \mathrm{mg}^{-1} \mathrm{~g} \mathrm{~min}^{-1} K_{\text {ad }}$ with an initial As(III) solution concentration of $0.0978 \mathrm{mg} \mathrm{L}^{-1}, \mathrm{pH}$ value at 7.0 , and the amount of $\mathrm{ZnO}$ loading at $0.01 \mathrm{~g} \mathrm{~L}^{-1}\left(10 \mathrm{mg} \mathrm{L}^{-1}\right)$. In comparison, for almost similar arsenic concentration of $0.1 \mathrm{mg} \mathrm{L}^{-1}$ and material loading 230 times less, we obtained much higher $K_{\text {ad }}$ of $0.837,5.99$, and $1.05 \mathrm{mg}^{-1} \mathrm{~g} \mathrm{~min}^{-1}$ (see Table 1) for curcumin contents of $0.5 \mathrm{mg}, 1.0 \mathrm{mg}$, and $2.0 \mathrm{mg}$ respectively. These $\mathrm{ZnO}$ micro-tubes themselves have surpassed the nanocrystalline $\mathrm{TiO}_{2}$ with a large specific surface area of $330 \mathrm{~m}^{2} \mathrm{~g}^{-1}$ synthesized by Meng and co-workers. ${ }^{61,62}$ In their study, the initial As(III) solution concentration was $2.0 \mathrm{mg} \mathrm{L}^{-1}$, the $\mathrm{pH}$ value was 7.0, and the amount of $\mathrm{TiO}_{2}$ was $0.2 \mathrm{~g} \mathrm{~L}^{-1}$. They reported $K_{\text {ad }}$ to be $0.00025 \mathrm{mg}^{-1} \mathrm{~g} \mathrm{~min}^{-1}$. The surface area of the adsorbent is not the only property that ensures the efficiency of the adsorbent; other factors are critical which include the type and number of surface functional groups on the adsorbents. And as the surface area of these nanostructures is no greater than the nanocrystalline $\mathrm{TiO}_{2}$ and probably the $\mathrm{ZnO}$ microtubes, these significant results suggest that curcumin conjugated $\mathrm{ZnO}$ nanostructures possess an excellent affiliation to As(III) due to the functionalities of the curcumin.

Since the rate for the reaction obeys pseudo second order kinetic model, the sorption capacity is proportional to the number of active sites occupied on the sorbent. Unlike the pseudo first order equation, the pseudo second order rate equation is likely to predict the behavior over the whole range of adsorption and the rate-limiting step is assumed to be chemical adsorption $^{63}$ involving valency forces through sharing or the exchange of electrons between the adsorbent and the metal ion. Therefore, the pseudo second order kinetics in present case suggests that the rate-limiting step is the surface adsorption, where the removal of As(III) from the solution is due to physicochemical interactions between the two phases. In our case the arsenic species present at pH 6 is $\mathrm{H}_{3} \mathrm{AsO}_{3}$. The $\mathrm{As}$ (III) species is thought to adsorb on the phenyl rings of curcumin and/or to the hydroxyls groups. Thus, we propose the possible reaction mechanisms as follows:

$$
\mathrm{Zn}(\text { cur- } \mathrm{OH}) \mathrm{O}+\mathrm{As}(\mathrm{III})+\mathrm{H}_{2} \mathrm{O} \rightarrow 2 \mathrm{Zn}(\text { cur-OAs }) \mathrm{O}+\mathrm{H}_{3} \mathrm{O}^{+}
$$

or,

$$
\mathrm{Zn}(\mathrm{cur}-\mathrm{Ph}) \mathrm{O}+\mathrm{As}(\mathrm{III}) \rightarrow \mathrm{Zn}(\mathrm{cur}-\mathrm{Ph}-\mathrm{As}) \mathrm{O}
$$

where $\mathrm{Zn}($ cur- $\mathrm{Ph}) \mathrm{O}$ and $\mathrm{Zn}(\mathrm{cur}-\mathrm{OH}) \mathrm{O}$ is phenyl rings and hydroxyl group on the $\mathrm{Zn}$ (cur)O surface, respectively. One might argue that if this is the possible mechanism, then higher curcumin content should reflect a higher adsorption capacity, which is not seen in the results. In fact, the higher curcumin content $(2 \mathrm{mg})$ incorporated in $\mathrm{ZnO}$ could be blocking the adsorption sites by stacking of phenyl rings or hydrogen bonding of hydroxyl groups of curcumin preventing adsorption of As(III). It is also important to note that dissolution of $\mathrm{ZnO}$ in water is about 1.6 to $7 \mathrm{mg} \mathrm{L}^{-1}$ depending on its size, ${ }^{64,65}$ therefore, a small amount of zinc ion is expected to get release during treatment of wastewater. Though incorporation of curcumin is anticipated to reduce the dissolution of $\mathrm{ZnO}$ due to chelation between zinc ion and curcumin, further study needs to be done for practical use of such materials in wastewater treatment or environmental monitoring because small amount of zinc ion could be toxic to a variety of aquatic organisms.

\section{Conclusions}

Curcumin-ZnO hybrid materials were synthesized successfully using a wet chemistry procedure. The nanostructures were found to have sub-micro grain-like morphology and wurtzite hexagonal crystal structure of ZnO. They showed very good crystalline quality. FTIR spectra showed that curcumin chelates with zinc through enol form but at the same time a weak link between hydroxyl or methoxy groups on the phenyl ring and $\mathrm{ZnO}$ is not ruled out. The doping of curcumin into $\mathrm{ZnO}$ resulted in the enhancement of the exciton emission at $358 \mathrm{~nm}$ and the substantial decrease of the visible emission around 560 in comparison to $\mathrm{ZnO}$ photoluminescence. Curcumin seemed to fill defects that were visible luminescence centers and at the same time prolonged e-h recombination. In contrast to naked $\mathrm{ZnO}, \mathrm{Zn}$ (cur)O could work as a fluorescence probe for arsenic sensing in the concentration ranges from 1 to $3000 \mathrm{ppb}$ in water, however, the fluorescence response started saturating after $3000 \mathrm{ppb}$ of arsenic in water. With a very low material loading, the $\mathrm{Zn}$ (cur)O nanostructures removed the As(III) contamination below the MCL from $100 \mathrm{ppb}$ samples within 30 minutes, and almost to zero within 3 hours. Bare ZnO didn't bring down the arsenic contamination below its MCL even after 
3 hours. The compound reached up to $75 \%$ removal/adsorption capacity with $903 \mathrm{ppb}$ concentrations after 3 hours with the same loading, which reflects the excellent capacity of removal for such a high arsenic concentration by $\mathrm{Zn}$ (cur)O. Kinetics of adsorption fitted very well to pseudo second order model with exceptional adsorption rates that reflected the high affinity of the compound to As(III). Although $\mathrm{Zn}$ (cur)O could sense arsenic in the $0-3000 \mathrm{ppb}$ concentration range by the fluorescence method rendering it a possible optical sensing materials and simultaneously offered an attractive alternative for a simple single-step treatment option to treat arsenic-contaminated natural water with high adsorption rates without the pretreatment requirement for current industrial and environmental practices, controlling the size and shape of such $\mathrm{Zn}$ (cur) O nanomaterials would further improve such capabilities and applications.

\section{Acknowledgements}

Financial support provided by Lebanese National Council of Scientific Research (NCSR) and American University of Beirut, Lebanon through URB, Kamal A. Shair Research Fund as well as Kamal A. Shair Central Research Science Laboratory (KAS CRSL) facilities to carry out this work is greatly acknowledged.

\section{References}

1 R. Shenhar and V. M. Rotello, Nanoparticles: Scaffolds and Building Blocks, Acc. Chem. Res., 2003, 36(7), 549-561.

2 B. I. Ipe, K. Yoosaf and K. G. Thomas, Functionalized gold nanoparticles as phosphorescent nanomaterials and sensors, J. Am. Chem. Soc., 2006, 128(6), 1907-1913.

3 A. B. Djurišić and Y. H. Leung, Optical properties of ZnO nanostructures, Small, 2006, 2(8-9), 944-961.

4 R. Janisch, P. Gopal and N. A. Spaldin, Transition metaldoped $\mathrm{TiO}_{2}$ and $\mathrm{ZnO}$-present status of the field, J. Phys.: Condens. Matter, 2005, 17(27), R657.

5 R. Wahab, S. G. Ansari, Y. S. Kim, H. K. Seo, G. S. Kim, G. Khang and H. S. Shin, Low temperature solution synthesis and characterization of $\mathrm{ZnO}$ nano-flowers, Mater. Res. Bull., 2007, 42, 1640-1648.

6 J. Nishio, M. Tokumura, H. T. Znad and Y. Kawase, Photocatalytic decolorization of azo-dye with zinc oxide powder in an external UV light irradiation slurry photoreactor, J. Hazard. Mater., 2006, 138(1), 106-115.

7 Y. Li, G. W. Meng, L. D. Zhang and F. Philip, Ordered semiconductor ZnO nanowire arrays and their photoluminescence properties, Appl. Phys. Lett., 2000, 76, 2011-2017.

8 K. Omichi, K. Kaiya, N. Takahashi, T. Nakamura, S. Okamoto and $\mathrm{H}$. Yamamoto, Growth of $\mathrm{ZnO}$ thin films exhibiting room-temperature ultraviolet emission by means of atmospheric pressure vapor-phase epitaxy, J. Mater. Chem., 2001, 11(2), 262-263.

9 A. H. Smith, E. O. Lingas and M. Rahman, Contamination of drinking-water by arsenic in Bangladesh: a public health emergency, Bull. W. H. O., 2000, 78, 1093-1103.
10 P. Kurttio, E. Pukkala, H. Kahelin, A. Auvinen and J. Pekkanen, Arsenic concentrations in well water and risk of bladder and kidney cancer in Finland, Environ. Health Perspect., 1999, 107(9), 705.

11 Y. Xia and J. Liu, An overview on chronic arsenism via drinking water in PR China, Toxicology, 2004, 198(1), 25-29.

$12 \mathrm{~K}$. Saha, Review of arsenicosis in west Bengal, Indiaa clinical perspective, Crit. Rev. Environ. Sci. Technol., 2003, 33(2), 127-163.

13 A. H. Welch, M. S. Lico and J. L. Hughes, Arsenic in ground water of the western United States, Groundwater, 1988, 26(3), 333-347.

14 N. E. Korte and Q. Fernando, A review of arsenic(III) in groundwater, Crit. Rev. Environ. Control, 1991, 21, 1-11.

15 T. S. Choong, T. Chuah, Y. Robiah, F. Gregory Koay and I. Azni, Arsenic toxicity, health hazards and removal techniques from water: an overview, Desalination, 2007, 217(1), 139-166.

16 S. Goldberg, Competitive adsorption of arsenate and arsenite on oxides and clay minerals, Soil Sci. Soc. Am. J., 2002, 66(2), 413-421.

17 B. Saha, R. Bains and F. Greenwood, Physicochemical characterization of granular ferric hydroxide (GFH) for arsenic(v) sorption from water, Sep. Sci. Technol., 2005, 40(14), 2909-2932.

$18 \mathrm{M}$. Borho and P. Wilderer, Optimized removal of arsenate(III) by adaptation of oxidation and precipitation processes to the filtration step, Water Sci. Technol., 1996, 34(9), 25-31.

$19 \mathrm{H}$. Lee and W. Choi, Photocatalytic oxidation of arsenite in $\mathrm{TiO}_{2}$ suspension: kinetics and mechanisms, Environ. Sci. Technol., 2002, 36(17), 3872-3878.

20 Y. Kim, C. Kim, I. Choi, S. Rengaraj and J. Yi, Arsenic removal using mesoporous alumina prepared via a templating method, Environ. Sci. Technol., 2004, 38(3), 924-931.

21 L. S. McNeill and M. Edwards, Review of iron pipe corrosion in drinking water distribution systems, J. Am. Water Works Assoc., 2001, 93(7), 88-100.

22 J. G. Hering, P.-Y. Chen, J. A. Wilkie, M. Elimelech and S. Liang, Arsenic removal by ferric chloride, J. Am. Water Works Assoc., 1996, 88(4), 155-167.

23 S. P. Pande, L. S. Deshpande, P. Patni and S. Lutade, Arsenic removal studies in some ground waters of West Bengal, India, J. Environ. Sci. Health, Part A: Environ. Sci. Eng. Toxic Hazard. Subst. Control, 1997, 32(7), 1981-1987.

24 R. Qiu, D. Zhang, Y. Mo, L. Song, E. Brewer, X. Huang and Y. Xiong, Photocatalytic activity of polymer-modified $\mathrm{ZnO}$ under visible light irradiation, J. Hazard. Mater., 2008, 156(1), 80-85.

25 S. H. Liao, H. J. Jhuo, Y. S. Cheng and S. A. Chen, Fullerene Derivative-Doped Zinc Oxide Nanofilm as the Cathode of Inverted Polymer Solar Cells with Low-Bandgap Polymer (PTB7-Th) for High Performance, Adv. Mater., 2013, 25(34), 4766-4771.

26 Z. Li, Y. Xiong and Y. Xie, Selected-control synthesis of ZnO nanowires and nanorods via a PEG-assisted route, Inorg. Chem., 2003, 42(24), 8105-8109. 
27 R. Hariharan, S. Senthilkumar, A. Suganthi and M. Rajarajan, Photodynamic action of curcumin derived polymer modified ZnO nanocomposites, Mater. Res. Bull., 2012, 47, 3090-3099.

28 R. Könenkamp, R. C. Word and C. Schlegel, Vertical nanowire light-emitting diode, Appl. Phys. Lett., 2004, 85(24), 6004-6006.

29 A. Goel, A. B. Kunnumakkara and B. B. Aggarwal, Curcumin as "Curecumin": From kitchen to clinic, Biochem. Pharmacol., 2008, 75(4), 787-809.

30 B. B. Aggarwal and K. B. Harikumar, Potential therapeutic effects of curcumin, the anti-inflammatory agent, against neurodegenerative, cardiovascular, pulmonary, metabolic, autoimmune and neoplastic diseases, Int. J. Biochem. Cell Biol., 2009, 41(1), 40-59.

31 R. M. Srivastava, S. Singh, S. K. Dubey, K. Misra and A. Khar, Immunomodulatory and therapeutic activity of curcumin, Int. Immunopharmacol., 2011, 11(3), 331-341.

32 T. Ganesh, J. H. Kim, S. J. Yoon, B.-H. Kil, N. N. Maldar, J. W. Han and S.-H. Han, Photoactive curcumin-derived dyes with surface anchoring moieties used in $\mathrm{ZnO}$ nanoparticle-based dye-sensitized solar cells, Mater. Chem. Phys., 2010, 123(1), 62-66.

33 D. Patra and C. Barakat, Unique role of ionic liquid [bmin] $\left[\mathrm{BF}_{4}\right]$ during curcumin-surfactant association and micellization of cationic, anionic and non-ionic surfactant solutions, Spectrochim. Acta, Part A, 2011, 79, 1823-1828.

34 M. Mouslmani, K. H. Bouhadir and D. Patra, Poly(9-(2diallylaminoethyl)adenine $\mathrm{HCl}$-co-sulfur dioxide) deposited on silica nanoparticles constructs hierarchically ordered nanocapsules: curcumin conjugated nanocapsules as a novel strategy to amplify guanine selectivity among nucleobases, Biosens. Bioelectron., 2015, 68, 181-188.

35 D. Patra, R. Aridi and K. Bouhadir, Fluorometric sensing of DNA using curcumin encapsulated nanoparticles assembled microcapsules from poly(diallyl ammonium chloride-co-sulfur dioxide), Microchim. Acta, 2013, 180, 5964.

36 D. Patra, E. El Khoury, D. Ahmadieh, S. Darwish and R. M. Tafech, Effect of Curcumin on Liposome: Curcumin as a Molecular Probe for Monitoring Interaction of Ionic Liquids with 1,2-Dipalmitoyl-sn-glycero-3-phosphocholine Liposome, Photochem. Photobiol., 2012, 88, 317-327.

37 E. El Khoury, M. Abiad, Z. G. Kassaify and D. Patra, Green synthesis of curcumin conjugated nanosilver for the applications in nucleic acid sensing and anti-bacterial activity, Colloids Surf., B, 2015, 117, 274-280.

38 R. N. Moussawi and D. Patra, Synthesis of Au Nanorods through Pre-Reduction with Curcumin: Preferential Enhancement of Au Nanorods Formation Prepared from CTAB Capped over Citrate Capped Au Seeds, J. Phys. Chem. $C, 2015,119,19458-19468$.

39 S.-S. Zhou, X. Xue, J.-F. Wang, Y. Dong, B. Jiang, D. Wei, M.-L. Wan and Y. Jia, Synthesis, optical properties and biological imaging of the rare earth complexes with curcumin and pyridine, J. Mater. Chem., 2012, 22, 2277422780 .
40 A. Ciszewski, G. Milczarek, B. Lewandowska and K. Krutowski, Electrocatalytic properties of electropolymerized $\mathrm{Ni}(\mathrm{II})$ curcumin complex, Electroanalysis, 2003, 15, 518-523.

41 A. K. Renfrew, N. S. Bryce and T. W. Hambley, Delivery and release of curcumin by a hypoxia-activated cobalt chaperone: a XANES and FLIM study, Chem. Sci., 2013, 4, 3731-3739.

42 M. I. Khalil, A. M. Al-Zahem and M. M. Qunaibit, Synthesis, characterisation and antitumor activity of binuclear curcumin-metal(II) hydroxo complexes, Med. Chem. Res., 2014, 23, 1683-1689.

43 M. I. Khalil, M. M. Al-Qunaibit, A. M. Al-zahem and J. P. Labis, Synthesis and characterization of $\mathrm{ZnO}$ nanoparticles by thermal decomposition of a curcumin zinc complex, Arabian J. Chem., 2014, 7, 1178-1184.

44 R. Dhivya, J. Ranjani, J. Rajendhran, M. Rajasekaran and J. Annaraj, $\mathrm{pH}$ responsive curcumin/ZnO nanocomposites for drug delivery, Adv. Mater. Lett, 2015, 6, 505-512.

45 L. Upadhyaya, J. Singh, V. Agarwal, A. C. Pandey, S. P. Verma, P. Das and R. P. Tewari, Efficient water soluble nanostructured ZnO grafted chitosan/curcuminnanocomposites for cancer therapy, Process Biochem., 2015, 50, 678-688.

46 E. El Khoury and D. Patra, Ionic liquid expedites partition of curcumin into solid gel but discourages into liquid crystalline phases of 1,2-dimyristoyl-sn-glycero-3phosphocholine liposome, J. Phys. Chem. B, 2013, 117, 9699-9708.

47 K. Mishra, R. K. Srivastava and S. G. Prakash, Photoluminescence and photoconductivity studies of $\mathrm{ZnO}$ nanoparticles prepared by solid state reaction method, $J$. Mater. Sci.: Mater. Electron., 2013, 24, 125-134.

48 S. N. A. El-Rahman and S. S. Al-Jameel, Protection of Curcumin and Curcumin Nanoparticles against Cisplatin Induced Nephrotoxicity in Male Rats, Scholars Academic Journal of Biosciences, 2014, 2(3), 214-223.

49 Z. Lu, J. Zhou, A. Wang, N. Wang and X. Yang, Synthesis of aluminium-doped ZnO nanocrystals with controllable morphology and enhanced electrical conductivity, J. Mater. Chem., 2011, 21(12), 4161-4167.

50 H.-M. Xiong, R.-Z. Ma, S.-F. Wang and Y.-Y. Xia, Photoluminescent $\mathrm{ZnO}$ nanoparticles synthesized at the interface between air and triethylene glycol, J. Mater. Chem., 2011, 21(9), 3178-3182.

51 T. M. Kolev, E. A. Velcheva, B. A. Stamboliyska and M. Spiteller, DFT and experimental studies of the structure and vibrational spectra of curcumin, Int. J. Quantum Chem., 2005, 102(6), 1069-1079.

52 S. Buddee, S. Wongnawa, P. Sriprang and C. Sriwong, Curcumin-sensitized $\mathrm{TiO}_{2}$ for enhanced photodegradation of dyes under visible light, J. Nanopart. Res., 2014, 16(4), 121.

53 S. Tayyari, H. Rahemi, A. Nekoei, M. Zahedi-Tabrizi and Y. Wang, Vibrational assignment and structure of dibenzoylmethane: a density functional theoretical study, Spectrochim. Acta, Part A, 2007, 66(2), 394-404. 
54 K. Krishnankutty and V. D. John, Synthesis, characterization and antitumor studies of metal chelates of some synthetic curcuminoids, Synth. React. Inorg. Met.-Org. Chem., 2003, 33, 343-358.

55 H.-M. Xiong, Photoluminescent $\mathrm{ZnO}$ nanoparticles modified by polymers, J. Mater. Chem., 2010, 20(21), 4251-4262.

56 J. Zhang, H. Liu, Z. Wang, N. Ming, Z. Li and A. S. Biris, Polyvinylpyrrolidone-Directed Crystallization of $\mathrm{ZnO}$ with Tunable Morphology and Bandgap, Adv. Funct. Mater., 2007, 17(18), 3897-3905.

57 S. H. Mousavi, H. Haratizadeh and H. Minaee, The effect of morphology and doping on photoluminescence of $\mathrm{ZnO}$ nanostructures, Opt. Commun., 2011, 284(14), 3558-3561.

$58 \mathrm{~S}$. Srivastava and Y. Srivastav, Removal of Arsenic from Waste Water by Using ZnO Nano-Materials, J. Mater. Sci. Eng. B, 2003, 3(8), 483-492.

59 W. Yang, Q. Li, S. Gao and J. K. Shang, High efficient As(III) removal by self-assembled zinc oxide micro-tubes synthesized by a simple precipitation process, J. Mater. Sci., 2011, 46(17), 5851-5858.
60 M.-S. Chiou and H.-Y. Li, Equilibrium and kinetic modeling of adsorption of reactive dye on cross-linked chitosan beads, J. Hazard. Mater., 2002, 93(2), 233-248.

61 S. Bang, M. Patel, L. Lippincott and X. Meng, Removal of arsenic from ground water by granular titanium dioxide adsorbent, Chemosphere, 2005, 60, 389-397.

62 G. Huan, J. du, X. Meng, Y. Sun, B. Sun and Q. Hu, Application of titanium dioxide in arsenic removal from water: a review, J. Hazard. Mater., 2012, 215-216, 1-16.

63 Y.-S. Ho and G. McKay, Pseudo-second order model for sorption processes, Process Biochem., 1999, 34(5), 451-465.

64 S. W. Wong, P. T. Leung, A. B. Djursić and K. M. Leung, Toxicities of nano zinc oxide to five marine organism: influence of aggregates size and ion solubility, Anal. Bioanal. Chem., 2010, 396, 609-618.

65 R. B. Seed, D. A. Ladner, C. P. Higgins, P. Wsterhoff and J. F. Ranville, Solubility of nano-zinc oxide in environmentally and biologically important matrices, Environ. Toxicol. Chem., 2012, 31, 93-99. 